
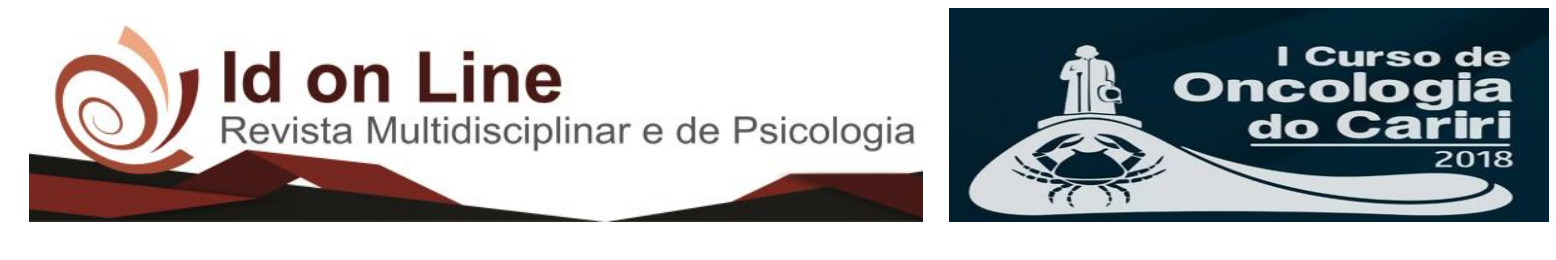

\title{
SARCOMA DE EWING: UM RELATO DE CASO
}

\author{
Ana Beatriz de Melo Alves ${ }^{1}$, Jefferson Marlon de Medeiros Pereira Maciel ${ }^{2}$, \\ Ana Laís Lacerda Rulim ${ }^{1}$, Gabriel Pinheiro Machado ${ }^{1}$, Marco Antônio Bezerra Rulim ${ }^{3}$.
}

Introdução: O Sarcoma de Ewing (ES), com incidência de 1/1.000.000 de pessoas, é, em sua maioria (80\%), uma neoplasia originária dos ossos, compreendendo o segundo tumor primário mais comum entre crianças e adolescentes. ${ }^{1,2}$ É uma entidade maligna agressiva, sendo os homens mais acometidos que as mulheres na razão de 1,5:1, e tendo maior prevalência entre pacientes caucasianos em comparação aos de origem africana. ${ }^{1}$ Objetivo: Relatar o processo investigativo de uma paciente com massa abdominal a esclarecer, até chegar ao diagnóstico etiológico preciso. Relato de caso: Paciente do sexo feminino, 12 anos, procedente de Barbalha - CE, compareceu ao ambulatório de Ginecologia do Hospital Maternidade São Vicente de Paulo queixando-se de dor em região pélvica iniciada há um mês, com irradiação para face anterior da coxa, agravada no período menstrual e associada à perda ponderal de $6 \mathrm{~kg}$ durante a evolução da dor. Procedeu-se à investigação diagnóstica com a realização de Ultrassonografia (USG) abdominal e Tomografia Computadorizada (TC) de pelve, esta evidenciou volumosa lesão expansiva heterogênea, predominantemente cística com várias septações grosseiras de permeio, de localização pré-sacral. Realizou-se laparotomia exploradora na expectativa da massa anexial evidenciada ter etiologia ovariana; no entanto, os achados cirúrgicos foram útero e ovários normais e massa de consistência fibro-cística volumosa retroperitoneal aderida ao reto. Como seguimento, foi realizada biópsia percutânea da lesão, que demonstrou neoplasia pouco diferenciada, sugestiva de Tumor de Wilms. Em complemento foi solicitado perfil imunohistoquímico que, em conjunto com os achados morfológicos, foi consistente com Sarcoma de Ewing/Tumor Neuroectodérmico Primitivo (PNET). Após resultado, em virtude do tipo de tumor e da idade, paciente foi transferida para o Hospital Infantil Albert Sabin, em Fortaleza. Conclusão: O caso dá luz à importância da persistência na investigação diagnóstica de patologias que não foram bem elucidadas a despeito da utilização de recursos de imagem e laboratoriais refinados. Apesar de doenças raras não fazerem parte do escopo médico cotidiano, seu diagnóstico não deve ser negligenciado ou menosprezado, pois oportuniza a obtenção de tratamento especializado.

Palavras-chave: Sarcoma de Ewing; Diagnóstico; Neoplasia infantil.

\footnotetext{
${ }^{1}$ Interno (a) de Medicina da Faculdade de Medicina Estácio de Juazeiro do Norte;

2 Acadêmico de Medicina da Universidade Federal de Campina Grande, campus Cajazeiras/P;

${ }^{3}$ Médico Cirurgião Geral pela Universidade Federal de Campina Grande, Hospital Universitário Alcides Carneiro, e

Professor assistente da disciplina de Clínica Cirúrgica II da Faculdade de Medicina Estácio de Juazeiro do Norte - FMJ

Autor Correspondente: anahmelo.abm@gmail.com.
}

1 Id on Line Rev. Mult. Psic. V.12, N. 40. 2018 - ISSN 1981-1179 EDIÇÃO ESPECIAL: I CURSO DE ONCOLOGIA DO CARIRI / II JORNADA DE PESQUISA QUANTI-QUALITATIVA EM ONÇOLOGIA. JUAZEIRO DO NORTE, 05 A 10 DE MARÇO DE 2018. Edição eletrônica em http://idonline.emnuvens.com.br/id 